\title{
GLOBALIZAÇÃO E IMPÉRIO: CONSIDERAÇÕES SOBRE A PROTEÇÃO DOS DIREITOS HUMANOS FRENTE ÀS NOVAS MODULAÇÕES DE SOBERANIA
}

\section{Mariana Chini ${ }^{1}$}

Resumo: O presente trabalho expõe linhas iniciais para a discussão sobre a proteção dos direitos humanos na contemporaneidade. Para isso, defende um aspecto basilar relativo a esse debate, que é o câmbio total das usuais noções de soberania, direito internacional e globalização, a partir de um novo conceito de Império e de, igualmente, novos arcabouços políticos e teóricos atinentes. Partindo das considerações de Michael Hardt e Antonio Negri, o trabalho situa o debate sobre a proteção dos direitos humanos como necessariamente coligado ao vácuo estatutário demonstrado por essa nova configuração político-jurídica, tornando insuficientes os cânones conhecidos para o enfrentamento do tema.

Palavras-chave: Direitos Humanos; Globalização; Império; Soberania;

\section{GLOBALIZATION AND EMPIRE: THOUGHTS ON THE HUMAN RIGHTS PROTECTION IN THE FACE OF NEW MODULATIONS OF SOVEREIGNTY}

\begin{abstract}
This paper presents the initial lines to the discussion of the human rights protection in the contemporaneity. To this end, defends an essential aspect of this debate, that is the total change of the usual notion of sovereignty, international law and globalization, from a new concept of Empire and, equally, new politic and theoretic framework. Starting from Michael Hardt and Antonio Negri, the work situate the debate about the human rights protection as necessarily colligate to the statutory void showing from this new politic-legal configuration, rendering the known canons insufficient to the coping of the subject.
\end{abstract}

Keywords: Empire; Globalization; Human Rights; Sovereignty

\section{INTRODUÇÃO}

Ainda é usual ou corriqueira a ideia de visualização padronizada de uma estrutura jurídica fundada em esteios como o Direito soberano coligado à ideia-base do Estado-nação. Desde uma cosmovisão moderna, inclusive, e o início das discussões acerca dos direitos humanos na toada incipiente de como o debate sobre eles se dá hoje, passou-se a compreender esses direitos como internos, ou seja, inerentes aos indivíduos considerados cidadãos, excluindo-se os demais de sua abrangência. O binômio formado a partir da noção basilar de

\footnotetext{
1 Mestranda em Direito na Universidade de Passo Fundo (UPF). Bolsista CAPES (Coordenação de Aperfeiçoamento de Pessoal em Nível Superior). Especialista em Direito do Trabalho e Processo do Trabalho (UNINTER). Especialista em Teologia (UNESA). Bacharel em Ciências Jurídicas e Sociais (UPF). Bacharel em Filosofia (UNISUL). Integrante do Projeto de Pesquisa "Estado de Direito, Sistemas de Justiça e crítica jurídica: horizontes de uma "nova política"” (UPF-RS). E-mail: mar.chini@ hotmail.com
}

Rev. de Teorias e Filosofias do Estado | e-ISSN: 2525-9652 | Porto Alegre | v. 4 | n. 2 | p. 34 - 53 | Jul/Dez. 2018 
Direito erigido à agenda de operacionalidade do Estado-nação, e essa internalização (como nota de solidificação) dos direitos humanos dentre os limites da soberania estatal, sofre, por óbvio, abalos em relação a um elementar número de suas (frágeis) premissas, mas persiste no tom simplório do encaixe de sua estrutura lógica.

Sobretudo contemporaneamente, um dos feixes de fragilidade dessa construção é visualizado na acirrada discussão teórica sobre conceitos e pilares pardigmáticos de modernidade e pós-modernidade. Debate que fragiliza e impõe tensão, sabidamente, na higidez de vários conceitos e ideias-motriz de acabamento moderno (entre elas a das próprias certezas e compactações como a própria soberania cerceada por fronteiras - em larga escala e sentido). Juridicamente tal discussão traz reflexos importantes no modo como os direitos humanos (e o direito em geral) se apresentam.

Segundo Michael Hardt e Antonio Negri, o Direito inescapavelmente passa por uma transição de um direito soberano de Estado-nação para um direito imperial pós-moderno, trazendo nessa mudança uma série de novos predicados e circunstâncias que, para além de um câmbio paradigmático que não seria de simples assimilação por si só, modifica a própria maneira de concepção dos termos soberania, ordem, e, mesmo, Direito. Tal transição (em seus pontos mais sensíveis) envolve vários eixos simbolicamente relacionados aos direitos humanos, como os conceitos de "guerra justa" e "inimigo" (HARDT; NEGRI, 2001).

Com base já nas dificuldades de implementação de mecanismos de proteção dos direitos humanos na modernidade (segundo o esquema alocado como padronizado), torna-se necessário discutir, igualmente, como tais mecanismos poderiam ser aplicados nesse dito contexto pós-moderno a partir não de uma singela superação, e, sim, de um câmbio conceitual e politicamente operacional dos próprios conceitos.

Esclarece-se que não se pretende no presente texto adentrar na discussão específica que compara e/ou opõe paradigmas e fatores emblemáticos de modernidade e pósmodernidade, pois ao trabalhar com a obra de Hardt e Negri e seus conceitos fundantes, partese do pressuposto de que o direito a partir da lógica de Império como ela vai discernida pelos autores é, sim, pós-moderno. Não no sentido da antiga querela sobre uma superação paradigmática linear, e sim como algo que se apresenta como uma versão ou modulação posterior, ou a partir de.

O trabalho será estruturado em dois capítulos ou partes, ambos tratando dos direitos humanos, mas cada um na perspectiva de uma configuração jurídica diferente e seu 
arcabouço. O primeiro tratará da perspectiva essencialmente moderna ligada à concepção de Direito soberano de Estado-nação e a transição desse viés para uma ideia internacionalizante (porém ainda estancada à noção de uma evolução jurídica linear dos conceitos). O segundo analisará os direitos humanos e o Direito imperial pós-moderno, a partir do lastro de nova visualização política desses institutos (que necessariamente é focada muito mais nas modulações políticas do poder efetivo do que em conformações defensáveis a partir de lastros lógicos, jurídicos e político-científicos padronizados).

Inicialmente, serão tecidas considerações especificamente sobre as conceituações de Estado e soberania em configurações standard, bem como sobre a concretude possível da proteção de direitos humanos a partir de uma modelagem que, em última análise, se remete à forma jurídica e política do Império Romano (molde inicial da noção de soberania e exemplo perfeito de uma lógica imperialista no sentido normalizado do termo). Já a segunda parte ou capítulo, será responsável por conceituar o direito Imperial - apropriação do próprio termo e da formatação dita pós-moderna do formato de Império e seus elementos - a partir das concepções de Hardt e Negri - demonstrando seu aspecto global (num sentido próprio do termo que ganha destaque no final do século $\mathrm{XX}$ com o pensamento dos autores), visando verificar como se concretizam os direitos humanos frente a estas novas configurações.

Tal estrutura visa possibilitar a compreensão das diferenças entre os conceitos de Direito tratados ao longo do trabalho, sempre trazendo a perspectiva dos direitos humanos em seu contexto, as formas como ela se apresenta (ou pode se apresentar) nessas diferentes percepções e as formas de violação e (novas) prioridades de sua proteção/efetivação no contexto.

O método utilizado para a construção do presente trabalho será o hipotéticodedutivo, partindo-se da concepção de direito soberano de Estado-nação para a concepção de direito Imperial pós-moderno, utilizando a abordagem qualitativa e o procedimento técnico bibliográfico através de consulta a obras referenciais da temática.

\section{LÓGICA IMPERIAL EM SUAS CONFIGURAÇÕES PRIMÁRIAS: SOBERANIA, GLOBALIZAÇÃO, E A PROTEÇÃo dOS DIREITOS HUMANOS ATÉ OS MOLDES JURÍDICO-POLÍTICOS MODERNOS}

Rev. de Teorias e Filosofias do Estado | e-ISSN: 2525-9652 | Porto Alegre | v. 4 | n. 2 | p. 34 - 53 | Jul/Dez. 2018 
Buscar-se-á ligeiramente neste tópico analisar como se efetivavam e se concretizavam (ou não) os direitos humanos e seu arcabouço protetivo, frente a uma noção de imperialismo conhecida na modernidade. Principalmente, em relação à figura da forma jurídico-política emblemática e persistente desde o Império Romano, coligada aos ideais de um direito soberano estritamente vinculado ao Estado-nação. Para tanto, iniciar-se-á com uma explanação em torno de conceitos - que embora já amplamente difundidos no meio jurídico sejam de grande relevância para o desenvolvimento da ideia ora apresentada, tais como, Estado e soberania. Em seguida, determinar-se-á qual a construção jurídica dos Estados-nação soberanos, buscando fazer-se vinculações com noções imperiais (literais, como o caso da Roma antiga, ou mesmo conceituais-técnicas, como em relação ao que se entende, na modernidade, por "imperialismo"), o qual será de grande importância para introduzir a noção posterior de Império pós-moderno no capítulo seguinte. Em meio a isso, buscar-se-á desvelar a padronização de tratamento da temática (direitos humanos) no bojo conceitual da soberania tipicamente assentada na esteira do Estado-nação

Os termos Estado e soberania passaram a ser utilizados a partir do século XVI, sendo que em relação ao primeiro, diz-se que só pode ser aplicado às sociedades após esta época: embora antes do período houvesse sociedades com uma essência similar em termos organizacionais, ou seja, com regras de convivência entre seus membros impostas por uma autoridade superior, ainda assim não poderiam receber tal designação como o termo denota comumente hoje (COSTA, 2011).

Quanto à soberania, este termo é primeiramente utilizado para dar legitimidade ao absolutismo monárquico, tendo sido amplamente aceito devido à influência do cristianismo, que buscava trazer à Europa uma espécie de unidade espiritual e política (NUNES JUNIOR, 2003). Ela pode ser definida como um poder de decisão acima do qual não há outro poder, sendo, portanto, supremo. Tal poder deve ser considerado sob dois aspectos, o interno e o externo. $\mathrm{O}$ aspecto interno demonstra a autoridade do Estado através de leis e normas que servem para regular os relacionamentos entre pessoas físicas ou jurídicas dentro do território desse próprio Estado. Já a soberania externa diz respeito as relações entre Estados diversos, nas quais não há subordinação ou dependência. Em resumo, a soberania interna é o poder do Estado dentro de seu território, enquanto a soberania externa é o poder independente de cada Estado em relação aos demais (STUBER, 1997). 
O conceito de soberania não é apenas jurídico, mas também religioso, pois suas origens remetem ao poder terreno de um chefe ao lado de um poder divino concedido pelos deuses. Por este motivo e dentro dessa acepção, os chefes de Estado consideravam-se com legitimidade absoluta para governar (BOSON, 2011).

A conformação de um conceito ou núcleo de características "imperiais" não pode passar ao largo da formatação-ótima que lhe sustenta tipicamente com o exemplo do conjunto político, jurídico, cultural e estrutural (de todo modo), que foi o Império Romano. Durante um largo período que adentra às raias do medievo (e cujo declínio, fim ou queda demarcada inclusive historicamente simboliza o próprio fim da Idade Antiga - em 476 d.C.), o poder político organizou-se sob as determinações da Igreja, do Império Romano e de poderes político-econômicos adjacentes a eles, de modo que a organização política era descentralizada, mas em termos. Uma descentralização que reconhecia a gestação do modelo feudal subsequente ao declínio imperial e o início da Idade Média, em sua fase incipiente, mas que ainda observada núcleos de poder esparsos no território sob o jugo final do imperador (NUNES JUNIOR, 2003, p. 2 e 3). Com seu modelo de expansão dominador, este império alargava suas fronteiras cada vez mais, de modo a ocupar a maior parte do território Europeu. A busca de Roma era por algo que se pode a posteriori definir como monarquia universal, e, para conquistar tal configuração, era imprescindível obrigar os povos estrangeiros conquistados a entregarem sua independência a ela e reconhecer sua soberania (BOSON, 2011, p. 2). Mas a visualização arquetípica de Roma como modelo imperial passa além de um poder bélico que simplesmente se expande territorialmente.

Dentre o que se pode conceituar como panoramas globalizantes, a expansão territorial, política, jurídica e cultural romana-imperial teve papel fundamental sob certo aspecto naquilo que simbolicamente se pode elucubrar entre os conceitos de nação, soberania, globalização e imperialismo - em si. Mesmo a partir do declínio da Roma imperial, a lógica expansiva do modelo romano e seu modelo de propagação de institutos e consolidação de seus domínios é exemplar no quesito: um aparelho engendrado que, unido à conjunção do império com a fé cristã e o papado, ao monopólio da universidade e às agendas do academicismo e da ciência autorizada, e contando com a aliança dos reinos conjugados ou subjugados, tratou de fortalecer um estilo de expansão e dominação incomensurável (NETO, 2006), cujo reflexo se nota a partir da influência ainda hoje não desbastada.

Rev. de Teorias e Filosofias do Estado | e-ISSN: 2525-9652 | Porto Alegre | v. 4 | n. 2 | p. 34 - 53 | Jul/Dez. 2018 
A tendência globalizante no caso, sabidamente, era uma tendência de exportação de domínios e de amplitude dessa soberania, calcada no alargamento territorial que trazia de arrasto a legitimidade política (e cultural) sobre a extensão dominada - ainda que com resquícios aparentes de independência e autonomia apaziguadoras. O imperialismo atuava como um agente de modernização que acabava por restringir a liberdade e submeter os povos colonizados, a partir também de um feixe que - via a tributação - restringia ao fim e ao cabo essa pretensa autonomia a um esquema de controle político-econômico extremamente centralizador (MORLEY, 2010, p. 70 e 71).

A partir do Renascimento, porém, e posteriormente dentre o período moderno, a globalização (assim considerada) adquire outra forma de visualização, mais aberta e comunicativa, ainda que a sombra das bases imperiais siga sendo plenamente identificável. $\mathrm{O}$ Direito e sua axiologia (cambiante e elegível) passa a ser o fator preponderante na centralidade de uma noção de soberania que se funde à legitimidade com e a partir desse Direito.

A invenção da imprensa é um fator que fortalece esse movimento global, bem como o fazem as grandes navegações. Mas é com a política e o Direito (em suas revigoradas configurações) que se abre espaço para as grandes revoluções posteriores da Modernidade, a partir do humanismo, do liberalismo e da democracia, que foram (e serão) importantes tanto no período moderno quanto nas configurações de uma noção de pós-modernidade (NETO, p. 2006, p. 2). O direito soberano de Estado-nação em relação ao critério do sujeito que estabelece a norma é aquele que tem como jurídicas as normas que são impostas pelo poder soberano, sendo que o ordenamento jurídico é definido por meio da soberania, e a soberania por meio do ordenamento jurídico, de modo que estes conceitos conversam entre si, referindose um ao outro de forma simbiótica (BOBBIO, 1994, p. 25). Uma nova fonte de legitimidade de poderio, frisa-se, e não um abandono da lógica do poderio em si mesma.

Já no tocante ao sujeito destinatário da norma (alvo da incidência do poder soberano), Costa (2011, p. 10) diz que os indivíduos aceitam a perda de sua liberdade natural em nome da garantia de individualidade civil, sujeitando-se às leis e à autoridade governamental. Neste sentido, uma das bases fundamentais do universo normativo segue sendo é a "fides romana", a "fé" de que os compromissos sociais, tanto privados quanto públicos, serão cumpridos através das leis, tratados, contratos e convenções, que servem como promessas aos cidadãos, sendo que a própria noção de fé nas normas vem da ideia de 
lealdade, ou seja, "fidelidade aos compromissos e às instituições". A figura do Estado de direito moderno, portanto, pressupõe “ (...) precisamente, o respeito dessa confiança mútua” (OST, 1999, p. 216).

Esta fé nos compromissos do Estado, porém, nem sempre é suficiente para garantir que as autoridades governamentais cumprirão com as promessas feitas, sendo que um dos campos que mais sofre com esta incerteza é o dos direitos humanos, sobre os quais historicamente se questionou se constituem uma categoria ético-jurídica com abrangência universal, ou se - ligados à própria soberania e por ela limitados - necessitam corresponder às exigências de um Estado-soberano. Neste segundo sentido, alguns teóricos argumentam que os direitos humanos não poderiam ser universais devido a grande quantidade de sistemas morais e jurídicos constantes na ordem mundial. Entretanto, para Barreto, tal argumento categoricamente "é consequência de uma leitura simplificada da questão" (BARRETO, 2004, p. 279-283).

Para Bobbio (1994, p. 22), o Direito não pode ser definido apenas do ponto de vista de uma norma jurídica única, sendo que para poder compreendê-lo é necessária a consideração de toda uma organização que determine como uma norma se torna eficaz e qual sua natureza, quais as sanções pelo seu descumprimento e quais seus destinatários. Tal organização provém de um ordenamento jurídico a partir do qual o Direito deve ser interpretado, assim, não se poderia resumir os direitos humanos a uma mera questão de direito interno.

Neste sentido, com o avanço da globalização (nos moldes do que se considera comumente hoje em torno do termo), além dos ordenamentos jurídicos nacionais, cada vez mais, tem-se a tendência de tratar de assuntos jurídicos no âmbito internacional. Seja no sentido de ingressos de particulares em trânsito, comércio e transferências contratuais internacionais, quanto no sentido de Estados que necessitam de comunicação jurídica entre si. Assim, a intervenção do direito internacional em questões internas de Estados soberanos tem sido cada vem maior, principalmente na tentativa de fortalecer a proteção dos direitos humanos em nível global (BERARDO, 2002), mas sem ignorar que a proteção ou amplificação internacional dessa proteção não é maior do que os interesses econômicos e políticos (e os ganhos disso advindos) que necessariamente colaboram mais para esse franquear e fronteiras e limites.

Rev. de Teorias e Filosofias do Estado | e-ISSN: 2525-9652 | Porto Alegre | v. 4 | n. 2 | p. 34 - 53 | Jul/Dez. 2018 
Um direito internacional otimizado permitiria que os representantes de todos os povos possam se pronunciar através de tratados, costumes e princípios internacionais, sendo que a partir destes últimos se podem definir (estipulação) quais os direitos reconhecidos internacionalmente, e se pode trabalhar com uma espécie de solidariedade que se traduza interna ou nacionalmente “(...) por uma repartição mais equitativa dos bens no interior de cada país, cuja ordem econômica não pode estar fundada na persistência de privilégios econômicos e sociais de certa classe" (MBAYA, 1997, p. 26-37). Ou seja: seria algo como um passo evolutivo para fora ou além das cercanias de um conceito de soberania tributário exclusivamente da lógica de Estado-nação. Um contrafluxo da própria modelagem de expansão global-imperial que paradoxalmente globaliza a expansão de uma soberania.

Nessa balança, o fiel se verificaria claramente em prol de uma defesa de direitos humanos como o espaço aberto e como medida da interligação de uma constante éticojurídica internacional: seria sua proteção o próprio elo de comunicação que excepcionaria as soberanias estanques.

Conforme explica Costa (2011, p. 12-13), foi Kelsen quem trouxe o estereótipo de um ordenamento jurídico hierarquizado, no qual a norma fundamental deveria ser uma norma de direito internacional cujos pactos se deveria cumprir. Para ele, ao se aceitar o direito internacional como superior ao direito interno, se estaria dificultando a configuração real da soberania, mas ao se aceitar a ideia inversa, de um direito interno superior ao direito internacional, se estaria constituindo uma configuração onde cada país consideraria seu ordenamento superior aos demais, o que impossibilitaria a solução de conflitos internacionais. Neste sentido, a proposta de Kelsen buscou adequar os ordenamentos internos e internacionais de modo que em casos de conflitos entre eles, o segundo prevaleceria sobre o primeiro, e com base em tal configuração a proteção dos direitos humanos em nível internacional seria muito mais eficaz.

Nesta seara, a ideia de direitos humanos enquanto exclusividade dos indivíduos nacionais de determinado Estado foi abandonada (ao menos em tese) a partir da criação das Nações Unidas e de instrumentos internacionais capazes de reconhecer a universalidade dos direitos humanos, dando espaço aos indivíduos para buscarem sua autodeterminação enquanto povos perante o plano internacional (MBAYA, 1997, p. 18).

De certo modo, a criação da ONU consegue captar alguns aspectos da proposta kelseniana de um sistema internacional enquanto fonte de toda a formação e constituição 
jurídica nacional - tal sistema é pensado por Kelsen, pois, para ele, os limites dos Estadosnação acabam obstruindo a ideia de Direito, sendo que as leis próprias dos Estados-nação conduziriam - logicamente - para uma universalidade do direito internacional. Tal situação terminaria com conflitos entre Estados com poder desigual entre si, simbolizando em tese o espírito de uma verdadeira comunidade internacional. Para ele, os Estados individuais deveriam ser vistos como entidades de uma mesma categoria, instituindo-se um Estado mundial e universal que possibilitasse a formação de uma comunidade também universal, que pudesse envolver os Estados individuais como uma capa (HARDT; NEGRI, 2001, p. 23 e 24).

Entende-se, portanto, que "as organizações internacionais são capazes de manter relações jurídicas diretas com outros sujeitos de direito internacional", podendo celebrar tratados, buscando a preservação da segurança coletiva entre países e congregando Estados soberanos em torno de soluções pacíficas (COSTA, 2011, p. 19), mas tal atuação das organizações internacionais tem cada vez menos relação com o Direito soberano de Estadonação e mais relação com o direito imperial pós-moderno que será abordado a seguir.

Há uma constante busca por uma nova ordem social por parte dos desfavorecidos, vítimas da marginalização social, tanto enquanto indivíduos singulares quanto enquanto grupos, buscando a possibilidade de uma maior autonomia e emancipação frente à ordem social e econômica imposta. "Tais reivindicações fazem parte de um movimento de libertação com vistas a substituir sistemas e práticas de opressão e exploração por estruturas e relações baseadas na justiça e no respeito aos direitos humanos para todos” (MBAYA, 1997, p. 18).

Enquanto no cerne da modernidade e seu conjunto paradigmático se cultivava uma ideia de direitos humanos somente no âmbito interno, a característica principal destes quando vistos do ponto de vista pós-moderno é o fato de suas normas se destinarem a todas as pessoas, não somente aos considerados nacionais (BARRETO, 2004, p. 249) e especialmente não somente com legitimidade de atuação e pilares calcados na soberania o Direito interno.

Com base nisto, passar-se-á a observar como se percebem os direitos humanos perante a transição de um direito soberano de Estado-nação para um direito imperial pósmoderno que trata muito mais do âmbito global do que individual, trazendo mudanças paradigmáticas aos conceitos da ordem jurídica secularmente implementada pela modernidade e cujas raízes permanecem no solo jurídico contemporâneo, embora muito menos profundas. 


\section{LINHAS E APORTES INICIAIS PARA SE PENSAR A PROTEÇÃO DOS DIREITOS HUMANOS EM UM CONTEXTO PÓS-MODERNO: O NOVO IMPÉRIO E A NOVA SOBERANIA}

A partir do presente momento, teremos como breve escopo analisar a transição do direito soberano de Estado-nação, que vigorou na modernidade, a grosso modo, para uma configuração de direito imperial pós-moderno, e verificar como os direitos humanos podem ser tratados (em âmbito protetivo) nesta distinta configuração jurídico-política.

Nessa questão, percebe-se que não houve um superar da lógica atrelada ao Estadonação e sua soberania correlata por uma abertura internacionalizante - jurídico-racionalhierárquica ou mesmo político-cooperativa - bem como não houve uma abandono da modulação imperial romana: o que se verifica é uma nova construção que absorve aspectos já deflagrados historicamente para uma construção de poderio ainda mais surpreendente e que flutua sobre estamentos jurídicos e políticos tradicionais potencializando os efeitos de domínio de um modo massivo.

Inicialmente é imprescindível tecer algumas considerações sobre a obra (já referenciada) que norteia o presente estudo: Império, de Michael Hardt e Antonio Negri. Conforme Faria (2003, p. 1), Império é uma espécie de "manifesto" para o século XXI que traz uma ideia de soberania que não está atrelada ao Estado-nação (tal como em sua conceituação acima apresentada), estando sim, baseado nos poderes econômicos e militares, bem como dos meios de comunicação, sendo um estudo da sociedade capitalista moderna que apresenta grande desenvolvimento da informação, aumento nas intervenções militares de organismos internacionais “ (...) em nome da paz e pela dominação do poder econômico”.

A problemática do Império é formada por diferentes singularidades, dentre as quais, uma ordem mundial que se expressa (também) como uma formação jurídica, a qual não é constituída nem pela interação espontânea de forças globais heterogêneas através do mercado econômico mundial, nem por uma universalização singela de ênfases e valores comuns, e nem ainda por uma única potência ou centro de forças globais. Isto porque tal formação jurídica passa por um processo de transição do Direito soberano de Estados-nação - e do direito internacional por ele criado - para um Direito imperial global pós-moderno, impulsionado pela constante crise que afeta a ordem internacional constituída a partir da Paz de Westfália (HARDT; NEGRI, 2001, p. 21-22). 
Uma das peculiaridades do Império é que nele não há qualquer Estado-nação que possa ser considerado oficialmente como a base do poder. Neste sentido, percebe-se (e as alusões são comuns e mesmo os autores as reconhecem) que os Estados Unidos são privilegiados com esta configuração Imperial dada uma espécie de domínio culturaleconômico-político de seu poderio planetário de influência, mas embora isto se dê, ainda assim não se pode falar em um "regime imperialista norte-americano" (FARIA, 2003, p. 5). Não se trata, pois, de uma teoria ou especulação que vise explicar ou conjecturar sobre o poder estadunidense nessa quadra histórica, senão que, talvez, seja uma leitura sobre a plataforma sobre onde esse poder bruto estadunidense encontrou assento frutífero.

Para compreender a configuração jurídica do Império é importante dar ênfase a certos momentos históricos que trouxeram impulso à formação de uma nova ordem mundial. Inicialmente, percebe-se que ao fim da Segunda Guerra Mundial se estendeu pelo globo uma ordem jurídica internacional que apontava para um novo conceito de ordem global, tendo como um de seus principais expoentes a formação da Organização das Nações Unidas (ONU), que é legitimada internacionalmente quando visa transferir o direito soberano para um centro supranacional, servindo como ferramenta para a transição a um sistema global. Sua criação traz alguns aspectos da proposta de Kelsen por um sistema internacional que fosse a fonte de toda a formação e constituição jurídica nacional (sobre o qual se tratou no capítulo anterior). Hardt e Negri visam, portanto, estudar a transição na brecha entre o conceito formal que sustenta a validade do processo jurídico numa fonte supranacional e a realização material desse conceito (HARDT; NEGRI, 2001, p. 22 -26).

Têm-se um sistema global, ou seja, um sistema cuja abrangência, para Hall, envolve o mundo todo e que “ (...) tem enfraquecido significativamente a soberania nacional e o "raio de ação' dos Estados-nação". Nele há um paradoxo, pois a globalização faz com que as coisas pareçam culturalmente as mesmas, através de "um tipo de americanização da cultura global", enquanto, ao mesmo tempo, as diferenças entre os indivíduos e os Estados se tornam cada vez maiores (HALL, 2009, p. 57).

Santos (2004, p. 244) então aduz que o que costumamos chamar de globalização “ (...) são, de facto, conjuntos diferenciados de relações sociais; diferentes conjuntos de relações sociais dão origem a diferentes fenômenos de globalização”, isto significa dizer que “ (...) não existe estritamente uma entidade única chamada globalização; existem, em vez disso, globalizações”. Para ele, portanto, “a globalização é o processo pelo qual determinada 
condição ou entidade local estende a sua influência a todo o globo e, ao fazê-lo, desenvolve a capacidade de designar como local outra condição social ou entidade rival”.

Neste novo contexto global, Hardt e Negri demonstram que os Estados-nação não são necessários para a consolidação do Direito Imperial, falando-se, então, em uma base de poder capaz de sustentar a nova ordem política, sendo que neste sentido adentram na esfera do Império o poder militar, o poder monetário e o poder da informação (FARIA, 2003, p. 5).

As ONGs também são, de acordo com Ruiz, uma nova forma de organização social que "produziram a figura (nova identidade) do voluntariado", o qual tem como característica o fato de ser um compromisso por vezes fraco e maleável, visto que:

\begin{abstract}
Um mesmo indivíduo pode aderir a um conjunto de identidades polimorfas, integrando uma atividade de líder estudantil e sendo um torcedor de futebol, um nacionalista convicto e um consumidor crítico, um crente religioso e um participante de uma associação de moradores, um defensor ecologista e um feminista, além de ser operário e ter o sentido de pertença (identidade) a uma banda de rock, etc. Pode ser várias destas coisas a um só tempo, ou todas elas" (RUIZ, 2003, p. 148).
\end{abstract}

Tal situação não seria conflitante caso os indivíduos se voluntariassem em todas estas ordens com o mesmo afinco e responsabilidade social, o problema se dá quando se escolhe dar prioridade a uma destas ordens em detrimento das outras, tornando as demais, projetos inacabados e desesperançosos, retirando a credibilidade das organizações voluntárias e contribuindo para a deturpação dos valores de solidariedade na ordem global.

Uma das primeiras dificuldades encontradas na busca por um poder político e uma fonte jurídica que sejam adequadas à globalização das relações econômicas e sociais se dá no fato de que muitos teóricos não reconhecem que a globalização e o avanço na produção capitalista são uma grande mudança nos paradigmas modernos. Embora o capitalismo tenha apresentado dimensões universais desde o começo, houve uma grande ruptura no modo de produção capitalista contemporâneo e nas relações de poder global, onde poder econômico e poder político são cada vez mais unidos em nome da ordem capitalista. Constitucionalmente falando, os processos de globalização são definições jurídicas que buscam uma configuração supranacional unificada de poder político. Para os teóricos que não compreendem as mudanças de paradigma torna-se difícil compreender o Império, pois acreditam que os Estados-nação capitalistas ainda exercem domínio imperialista sobre outras nações, de modo que este não seria uma novidade, mas sim uma forma aperfeiçoada de imperialismo (HARDT; NEGRI, 2001, p. 26 e 27).

Rev. de Teorias e Filosofias do Estado | e-ISSN: 2525-9652 | Porto Alegre | v. 4 | n. 2 | p. 34 - 53 | Jul/Dez. 2018 
A globalização e o aumento nas tecnologias de mercado levam a um declínio da soberania dos Estados-nação, sendo que tal situação torna imprescindível a busca por uma nova forma de soberania capaz de agir com base em uma regra única de governo, ou seja, o Império (COSTA, 2011, p. 23).

Trata-se, na verdade, da construção de uma nova noção de direito, que engloba todo o espaço civilizatório do planeta; de um novo registro de autoridade, que atua de modo soberano e permanente; e de um projeto voltado para a produção de normas e de instrumentos legais de coerção para que se possa manter sobre o seu total controle os resultados políticos de qualquer acontecimento no âmbito global. Condição que leva a nova ordem a se colocar como uma necessidade capaz de garantir a harmonia nas relações sociais e no cenário mundial, conduzindo as "guerras justas" e combatendo as manifestações rebeldes que comprometem a ordem global (NASCIMENTO, 2014, p. 106 e 107).

Os conflitos entre as diversas potências imperialistas foram substituídos por um poder único que as organiza e trata de acordo com uma noção de direito pós-colonial e pósimperialista, e a partir disto inicia-se o estudo do Império, ao buscar-se desvendar a nova noção de Direito, "ou melhor, um novo registro de autoridade e um projeto original de produção de normas e de instrumentos legais de coerção que fazem valer contratos e resolvem conflitos" (HARDT; NEGRI, 2001, p. 27). Mas existe um grande problema no Império, que se dá pelo fato de que quando este não respeita devidamente os direitos humanos e a democracia, acaba levando a sociedade ao encontro do totalitarismo (FARIA, 2003, p. 6).

Os autores atentam para as configurações jurídicas de constituição do Império no início da obra, pois estas dão bons indicadores para o processo de constituição imperial, na qual há uma transição da lei internacional tradicional (a qual definida por tratados e contratos) para um novo poder soberano e supranacional. Tal transformação jurídica funciona como "sintoma das mudanças da constituição material biopolítica de nossas sociedades", que influenciam não apenas na lei internacional e nas relações internacionais, mas também nas relações de poder de cada país. Este estudo encaminha-se para o cerne da teoria política do Império, onde há uma problemática acerca da primazia supranacional no tocante a sua legitimação e sua prática, evidenciando problemas políticos, culturais e ontológicos (HARDT; NEGRI, 2001, p. 27 e 28).

Antes de se abordar o conceito jurídico de Império, deve-se dar atenção à genealogia do conceito em si, o qual remonta claramente à tradição europeia, em especial, como já anteposto, à Roma antiga, onde as configurações jurídico-políticas imperiais foram associadas às origens cristãs das sociedades da Europa. Neste tocante, a concepção de Império abrange

Rev. de Teorias e Filosofias do Estado | e-ISSN: 2525-9652 | Porto Alegre | v. 4 | n. 2 | p. 34 - 53 | Jul/Dez. 2018 
categorias jurídicas e valores éticos universais e os faz funcionar conjuntamente, trazendo como bandeira o ideário de paz e justiça para todos. O conceito de Império é, então, apresentado como um poder único capaz de manter a paz e produzir verdades éticas na sociedade, de modo que a força é passada para um poder único, que pode e deve conduzir quando necessário, “ (...) 'guerras justas’ nas fronteiras contra os bárbaros e, no plano interno, contra os rebeldes”. Pode-se dizer, portanto que, desde o início, “ (...) o Império põe em movimento uma dinâmica ético-política, que jaz no coração do seu conceito jurídico”, o qual envolve a noção de um direito que atua na construção de uma nova ordem que toma o espaço ilimitado e universal da civilização e abrange o tempo dentro de seu fundamento moral. A ordem do Império, portanto, não está nem no passado, nem no presente, mas sim na permanência, na eternidade (HARDT; NEGRI, 2001, p. 28 e 29).

A soberania tradicionalmente e originalmente assentida (núcleo duro do próprio conceito), em sua versão mais bruta, já não pode mais ser reivindicada por nenhuma entidade após a queda do Império Romano. Mesmo assim, o conceito amplo e reformado de soberania continua presente na sociedade atual e a eventual resposta para o questionamento sobre como e com que corporificação isso ocorre está em retirar deste conceito "suas vestes emotivas, metafísicas, que lhe dão todos os sentidos, inclusive o da violência", reconhecendo-lhe somente a característica da "absoluteidade jurídica", para que se possa utiliza-lo como valor positivo e instrumento pacífico para qualquer ordem jurídica (BOSON, 2011, p. 6).

Negri e Hardt apresentam a concepção de um sistema soberano com duas frentes: a soberania interna, já tratada no capítulo anterior, e a soberania imperial, que complemente a primeira, mas que não possui limites, envolvendo todo o mundo, de modo que não pode ser chamada de exterior por agregar todo o tempo e o espaço em sua conceituação. Tal soberania imperial deveria ser utilizada para inibir as guerras civis entre os Estados, pois tais guerras “tomam repercussão global e são indesejadas pela sociedade mundial em geral” (COSTA, 2011, p. 24).

Demonstra-se uma mudança de forma na soberania, e esta é, em partes, promovida pela ideia de "inimigo". Até a Guerra Fria o conceito era fácil e sobretudo imageticamente tido como a outra potência soberana (embate entre Estados Unidos e União Soviética, traduzindo embates simbólicos entre modos de produção capitalista e comunista, bem como uma visual contraposição entre ocidente e oriente, ou entre competitividade liberal e desenvolvimento planificado). Contudo na atualidade, tal concepção simplista já não é 
possível, pois não há um único sujeito ou oponente soberano evidente no plano internacional, mas sim vários (COSTA, 2011, p. 24). Volta à tona, então, a chamada Guerra Justa que não atua como defesa ou resistência, mas como atividade que se justifica em si mesma. Ademais, esta modalidade de guerra utiliza-se de dois elementos muito distintos em suas configurações: "o primeiro, a legitimidade do aparelho militar desde que eticamente fundamentado, e segundo, a eficácia da ação militar na conquista da ordem e da paz desejadas". Neste tocante, a figura do inimigo é banalizada na atualidade - através da repressão policial cotidiana, por exemplo - e absolutizada, vendo-se o inimigo como alguém que ameaça a ordem ética em sua totalidade (HARDT; NEGRI, 2001, p. 31).

O Império utiliza-se, portanto, de concepções morais para justificar suas invasões em territórios alheios, sendo um exemplo desta situação a tentativa dos Estados Unidos de unir forças com os demais países soberanos para combater o terrorismo, justificando sua expansão militar ao redor do mundo (NASCIMENTO, 2014, p. 110 e 111).

Neste sentido, Ruiz (2003, p. 131) traz a ideia de que:

\begin{abstract}
Atualmente não é mais possível legitimar a existência da escravidão, porém o desencadeamento de guerras (justas) em nome dos direitos humanos é uma amarga experiência que ainda não terminamos de assimilar. Despedimos o século XX com uma guerra justa contra Sérvia, em nome dos direitos humanos (após outra guerra, inacabada, contra o Iraque, para defender o direito da liberdade do Kuwait), e inauguramos o século XXI com outra guerra (justa) contra o Afeganistão, em nome da defesa da liberdade, do direito natural de vingança e da defesa dos direitos humanos. Para defender a liberdade e os direitos humanos se enviam tropas, norteamericanas evidentemente, às Filipinas, Bolívia, Colômbia, Etiópia, Arábia Saudita, etc. Sobram comentários sobre os sentidos ocultos destas legitimações supostamente racionais, efetivamente simbólicas, da guerra justa.
\end{abstract}

Percebe-se, portanto, que embora com a transição do direito soberano de Estadonação para um direito imperial pós-moderno se tenha em potencial uma maior abrangência na proteção aos direitos humanos - sendo que os mesmos já não são vistos apenas como direitos internos de cada Estado soberano, mas sim como direitos universais - por vezes estes são utilizados como escudo para proteger ações ligadas não à proteção dos indivíduos enquanto detentores de direitos no âmbito internacional, mas sim, à proteção do poder social e econômico de determinados países na ordem mundial.

Uma dita proteção de direitos humanos no panorama do Império em sua configuração pós-moderna não traz ares de um plano de abertura ou abandono dos enclaves de soberania, como previam visões cooperativistas ou como o próprio conjunto configurado

Rev. de Teorias e Filosofias do Estado | e-ISSN: 2525-9652 | Porto Alegre | v. 4 | n. 2 | p. 34 - 53 | Jul/Dez. 2018 
positivamente para uma ordem jurídica hierárquica internacional. Não traz, igualmente, uma expansão do feixe de direitos a reboque - ou como colateralidade - de uma nova expansão global centrada mercadologicamente. Muito menos o é um primordial imperativo de uma cruzada que tem na defesa de pautas éticas e axiológicas mínimas um objetivo utópico e uma empresa moral. Seria, sim, uma espécie de argumento ou artífice que funcionaria ao reverso de uma abertura: seria um instrumento (mais um) de imposição e reforço de lógicas que criam aparentes comunidades valorativas, como justificação do próprio avançar imperial.

O plano parece residir justamente no uso da proteção de direitos humanos como plataforma (uma das mais eficientes, no quesito) para a absorção dos conceitos que permitam que o Império (na linha do que trazem Hardt e Negri) siga apoiado na justeza de suas "guerras justas" muito mais do que em qualquer dado de soberania materialmente palpável via conformação política e jurídica. O Império nessa versão não possui um estatuto embargável e a solidez de sua expansão contrasta com o tom etéreo ou liquefeito de como perante ele se veem os próprios pilares modernos de soberania que conhecemos.

\section{CONSIDERAÇÕES FINAIS}

É possível estabelecer um câmbio notável e necessariamente preocupante no modelo de difusão globalizada de fatores comuns e de valores que se opera nessa quadra histórica. Os modelos modernos, tipicamente, não deram lugar a uma específica gama paradigmática trans ou pós moderna necessariamente (tal como nas antigas querelas, uma espécie de superação paradigmática linear). Em contrário: as fronteiras (literais e figurativas) da modernidade não foram ultrapassadas por um esfacelamento coordenado de sua própria caracterização de limite. Foram submergidas em uma nova lógica que, apesar de estar (inclusive geograficamente) mais aparentemente ligada à proposta de internacionalização frente a uma soberania interna estanque, demonstram um novo tom de funcionamento. Um tom quiçá atrelado à imagética de uma dominação à moda do Império Romano original do que a uma globalização otimista como evolução da cordialidade internacional ou como estipulação de pautas prioritárias universais. Ou uma junção dos mais poderosos aparelhos e conceitos de ambos para a gestação de uma nova e inimaginável fonte de domínios, expansões, controles e subjugações.

Rev. de Teorias e Filosofias do Estado | e-ISSN: 2525-9652 | Porto Alegre | v. 4 | n. 2 | p. 34 - 53 | Jul/Dez. 2018 
Nesse sentido, uma dominação imperial, não por um Império configurado sob um rosto ou uma bandeira de cores e pautas conhecidas e delimitadas, mas sim a pura expressão trazida por Hardt e Negri, relativa a um "não lugar sem fora". Uma autêntica nova ordem onde uma conformação como a da forma jurídica não serve como instrumentalizadora da racionalidade, mas é ao mesmo tempo instrumento e construção da ordem. Uma ordem que não apenas revive, mas perpetua e atualiza noções palpáveis (e sempre mutantes, convenientemente) sobre os objetivos casuais e os inimigos ocasionais.

Nessa esfera, percebe-se que se o teor globalizante triunfou às avessas, vez em que a lógica eminentemente monolítica de um Império Romano (cuja queda inclusive encerra uma era) e sua junção com anseios sistematizadores modernos não foram superadas por uma comunhão global, nem muito menos por uma sistematização (à moda kelseniana) racional de hierarquias jurídicas padronizadas. A globalização triunfante (também em sentido econômico - sumamente neoliberal) é ao mesmo tempo constituinte e exemplo, é ao mesmo tempo forja e produto de uma lógica que não encontra precedente - senão raízes - no desenvolvimento da noção.

Nesse campo, a perspectiva de proteção de direitos humanos tem um claro entrave uma vez que não há também para ela um esteio ou refúgio jurídico (e político) de apelação. A previsão de superação dos quesitos de soberania e do próprio arcabouço de um Estado-nação e suas características e predicados se dá (ou deu) não por um modelo de estratégia crítica, e sim por uma conjuntura potencializada e distinta onde a abertura (ou fechamento) de fronteiras é fator contingencial mediado por outras estratégias e intencionalidades e fatores por vezes obscuros, por ora clarividentes.

A estrutura global de um mundo pós-moderno traz maior flexibilidade ao modo como os direitos e deveres são socialmente caracterizados, visto que uma configuração não centrada em paradigmas inertes é capaz de apresentar maior possibilidade de trânsito entre concepções antes consideradas unas e imodificáveis.

A passagem de uma configuração de direito soberano, estanque, envolto no Estadonação, para um direito aberto, além-fronteiras, adaptável, é um exemplo de como a globalização é capaz de transmutar paradigmas há muito impostos e consolidados como verdades únicas. 
Nesta seara, o contexto pós-moderno é capaz, não só, de contribuir para a emergência de novos direitos, como também, de expandir a abrangência de direitos já consolidados no Ocidente como inerentes ao ser humano. É o caso dos direitos humanos.

Ao expressar maior maleabilidade frente a contextos inéditos, os direitos humanos tornam-se capazes de envolver um número de situações e indivíduos muito maior, contribuindo para a construção de um direito pós-moderno global e, ao mesmo tempo, local, pois leva em consideração todas as características intrínsecas ao meio onde se apresentam.

A contrapartida, porém, é inevitável, visto que ao tornar-se flexível, maleável e abrangente, o direito pós-moderno é capaz de se inserir em configurações que não lhe cabem, agindo, teoricamente, em nome da proteção de direitos individuais ou coletivos, como os direitos humanos, quando em verdade, age em benefício de expressões globais econômicas e políticas.

É por este motivo que ao tratar do Império em sua particular formatação, Hardt e Negri tomam o cuidado de expressar suas preocupações acerca das máscaras por ele utilizadas, tendo em conta o fato de que, por vezes, ao aparentar cuidado e proteção com os seres humanos, apenas estão disfarçando sua real preocupação: com o poder bélico e econômico.

Pensar a proteção dos direitos humanos - e a própria conceituação ou base material para os mesmos - passa a ser algo coligado à imprescindibilidade de não mais se ater a critérios estatutários que imaginam guaridas essencialmente modernas ou planos visivelmente ingênuos relativos a uma força ético-normativa. Pensar essa proteção requer a análise a partir da nova visão de Império e da alarmante impossibilidade de sequer se contar com as falhas e contingências das versões antes conhecidas de sedimentos de Estado-nação, soberanias e inter-relações conceituais. A comunicação ou abertura entre as soberanias internas tendo os direitos humanos como espécie de pista de interesses comuns não logrou êxito em se efetivar senão que foi perfeitamente cooptada para via de acesso e contágio de uma nova lógica imperial. Pensar os direitos humanos e seu âmbito protetivo é pensar contra essa própria lógica que inclusive luta para nem necessariamente dominar o conceito, mas para se incrustar no próprio.

\section{REFERÊNCIAS}

Rev. de Teorias e Filosofias do Estado | e-ISSN: 2525-9652 | Porto Alegre | v. 4 | n. 2 | p. 34 - 53 | Jul/Dez. 2018 
BARRETO, Vicente de Paulo. Multiculturalismo e direitos humanos: um conflito insolúvel? In: BALDI, César Augusto. (Org). Direitos humanos na sociedade cosmopolita. Rio de Janeiro: Renovar, 2004.

BERARDO, Telma. Soberania, um novo conceito? Revista de Direito Constitucional e Internacional| vol. 40/2002 | p. 21 - 45 | Jul - Set / 2002. DTR\2002\774

BOBBIO, Norberto. Teoria do ordenamento jurídico. Introdução: Tercio Sampaio Ferraz Júnior. Tradução: Claudio de Cicco e Maria Celeste C. J. Santos. Revisão técnica: João Ferreira. - Brasília: Editora Universidade de Brasília, $4^{a}$ edição, 1994.

BOSON, Gerson de Britto Mello. Conceituação jurídica da soberania do Estado. Doutrinas Essenciais de Direito Constitucional | vol. 2 | p. 293 - 306 | Maio / 2011. DTRL2012 21026.

COSTA, Rafael Iuchini Alves. O conceito de soberania no mundo contemporâneo. Revista de Direito Constitucional e Internacional | vol. 76/2011 | p. 389 - 426| Jul - Set / 2011. DTR\2011\2494

FARIA, Elisa Teixeira de. Globalização e Autonomia Municipal. Revista Brasileira de Direito Municipal - RBDM. Editora Fórum: Belo Horizonte, ano 4, n. 8, abr. / jun. 2003.

HALL, Stuart. A questão multicultural. In: Da diáspora: identidades e mediações culturais. Tradução de Adelaine La Guardia Resende et al. Belo Horizonte: Editora UFMG, 2009.

HARDT, Michael. NEGRI, Antonio. Império. Tradução de Berilo Vargas. - $2^{\mathrm{a}}$ ed. - Rio de Janeiro: Record, 2001.

MBAYA, Ettiene-Richard. Gênese, evolução e universalidade dos direitos humanos frente à diversidade de culturas. In: Revista Estudos Avançados. n.30, São Paulo: USP, 1997.

MORLEY, Neville. The Roman Empire: Roots of Imperialism. Pluto Press: [S/l], 2010. Disponível em: https://www.jstor.org/stable/j.ctt183pb5x.8 - Acesso em: 23/07/2018.

NASCIMENTO, Mariângela Moreira. A nova ordem global e a emersão de novos sujeitos (reflexões a partir do pensamento de A. Negri e M. Hardt). Revista Profanações - Ano 1, n. 1, p. 104-123, jan./jun. 2014. Disponível em: https://repositorio.ufba.br - Acesso em: 28/07/2018.

NETO, Diogo de Figueiredo Moreira. Governo e Governança em Tempos de Mundialização: Reflexões à Luz dos Novos Paradigmas do Direito. RDA - Revista de Direito Administrativo. Editora Fórum: Belo Horizonte, ano 2006, n. 243, set. / dez. 2006

NUNES JUNIOR, Venilto Paulo. O conceito de soberania no século XXI. Revista de Direito Constitucional e Internacional | vol. 42/2003 | p. 144 - 166 | Jan - Mar / 2003. DTR\2003\53. 
OST, François. O tempo do direito. Tradução: Maria Fernanda Oliveira. Éditions Odile Jacob, 1999.

RUIZ, Castor M. M. Bartolomé. O (ab)uso da tolerância na produção das subjetividades flexíveis. In: SIDEKUM, Antônio. (Org). Alteridade e multiculturalismo. Ijuí: Ed. Unijuí, 2003.

SANTOS, Boaventura de Sousa. Por uma concepção multicultural de direitos humanos. In: BALDI, César Augusto. (Org). Direitos humanos na sociedade cosmopolita. Rio de Janeiro: Renovar, 2004.

STUBER, Walter Douglas. Soberania e Direito Internacional. Revista de Direito Constitucional e Internacional | vol. 18/1997 | p. 223 - 225 | Jan - Mar / 1997. DTR\1997\52. 